\title{
Do Individual Needs Moderate the Relationships between Organizational Citizenship Behavior, Organizational Trust and Perceived Organizational Support?
}

\author{
Jo Ann Duffy \\ Juliana Lilly \\ Sam Houston State University
}

\begin{abstract}
The functional approach to human behavior is used to study the impact of intrinsic motivators of organizational citizenship behavior (OCB). Specifically, McClelland's needs for affiliation, achievement, and power are investigated as possible moderators in the relationship between OCB and organizational trust and perceived organizational support (POS). Survey data from 700 employees were analyzed using regression analysis. Results indicate the need for achievement and the need for power moderate the relationships between OCB and organizational trust and POS but in an unexpected manner. This study is significant because it enhances our understanding of what motivates OCB.
\end{abstract}

Key words: individual needs, organizational citizenship behavior, trust, organizational support

\section{Introduction}

Organizations want employees to be productive and cooperative in the workplace, but employee behavior is often dependent upon organizational factors such as culture or leader support. For example, many studies have found that employees voluntarily go above and beyond their normal job duties if they trust the organization (Dirks \& Ferrin, 2000) or if they believe the organization cares about them (Eisenberger, Armeli, Rexwinkel, Lynch \& Rhoades, 2001). However, there is a dearth of research on how individual employee characteristics may influence these relationships between employee behavior and perceived organizational trust or support.

The purpose of this study is to expand the current literature by using the functional approach to human behavior to examine how individual employee needs impact an employee's willingness to go above and beyond their normal job duties to help their organization. In other words, what motivates the employee to engage in extra-role behaviors that help the organization?

The functional approach to human behavior assumes that people choose to engage in behavior that meets their needs, and essentially asks the question: What need is being met by the behavior in question? (Penner, Midili, Kegelmeeyer, 1997). In our study, the behavior in question is organizational citizenship behavior (Organ, 1988; 1994; Organ \& Ryan, 1995), exemplified when individual workers volunteer and go beyond their role requirements to perform activities that benefit the organization or colleagues (Parnell \& Crandall, 2003; Podsakoff, Ahearne \& MacKenzie, 1997; Podsakoff \& MacKenzie, 1994). We argue that people engage in organizational citizenship behavior (OCB) because they are motivated to do so. In other words, they will perform OCB because OCB meets their personal goals and needs.

Individual needs for achievement, power and affiliation were identified by McClelland (1961) as important to understanding what motivates human behavior. We believe these needs, intrinsic motivators of behavior, may influence an individual's tendency to perform OCB, and that they may strengthen 
previously established relationships between organizational trust and OCB (Dirks \& Ferrin, 2000) and between perceived organizational support and OCB (Eisenber, et al., 2001).

This study examines motivators that may influence employees to engage in extra-role behaviors in the workplace. We follow the functional approach to human behavior and argue that employees' specific needs for achievement, affiliation, and power influence whether they engage in OCB. Specifically, this study examines whether McClelland's needs moderate the relationships between OCB, organizational trust, and perceived organizational support.

\section{Background Literature Review}

Research has shown that organizational effectiveness is enhanced when individual workers volunteer and go beyond their role requirements to perform activities that benefit the organization or colleagues. (Podsakoff, Ahearne, \& MacKenzie, 1997; Podsakoff \& MacKenzie, 1994). Such actions, known as Organizational Citizenship Behaviors (OCB) are exemplified by actions such as helping coworkers or performing extra-job activities (Organ, 1988; 1994; Organ and Ryan, 1995). Because OCBs are behaviors that are beyond the "call of duty" they are always discretionary in nature (Parnell \& Crandall, 2003). OCB includes at least two dimensions: 1. behavior directed at individuals (OCBI) or altruistic behavior directed at helping individuals and 2. behavior directed toward the organization (OCBO) or impersonal behavior demonstrated by being a conscientious, compliant, good citizen (Smith, Organ, \& Near, 1983; Williams \& Anderson, 1991). Previous research has shown that perceptions of organizational support and organizational trust are linked to increased OCB. There is also some evidence that certain motivators have a main effect on OCB. However, there is no study that explores the moderating effect of motivators. Our study seeks to fill this gap in our understanding of OCB. Figure 1 shows the proposed theoretical model for our study. Following are descriptions of the key variables in this model.

Organizational trust is defined as an individual's belief that others (individual or group) will make a good faith effort to keep commitments, be honest, and not take advantage of another (Cummings \& Bromiley, 1996). Perceived Organizational Support (POS) refers to workers' belief in how much the organization values their contributions and cares about their wellbeing (Eisenberger, Huntington, Hutchison \& Sowa, 1986). Researchers have found strong positive correlations between organizational trust and perceived organizational support (Alder, Noel \& Ambrose, 2006; DeConinck, 2010; Ferres, Connell \& Travaglione, 2005) as well as positive links between trust and OCB (Chiaburu \& Lim, 2008; Erturk, 2007; Rubin, Bommer \& Bachrach, 2010; Wong, Ngo \& Wong, 2006)

Individual needs for achievement, power and affiliation are well recognized motivators of human behavior (McClelland 1961). Need for achievement refers to the drive to excel, to succeed; the need for power refers to the need to have influence over others; and the need for affiliation refers to the desire for close interpersonal relationships (McClelland, 1961; McClelland and Stahl, 1986). According to Piccolo and Colquitt (2006), intrinsic motivators are determinants of OCB. These researchers reason that employees perform OCBs "that go beyond the formal requirements of a job to satisfy some higher-order individual need or to align work behavior with individual values. Because such behaviors are less likely to be formally rewarded than are required job behaviors, they are presumably performed for selfgenerated, intrinsic reasons. (p.330)" Since this explanation of OCB indicates that OCB is intrinsically motivated, we argue that employees' needs, specifically needs for achievement, power and affiliation, will influence how motivated they are to perform OCB and will strengthen the relationship between organizational trust and perceived support and OCB.

\section{Hypotheses Development}

To discuss perceived organizational support and organizational trust as antecedents of OCB, we draw from social exchange theory (Blau, 1964) and the norm of reciprocity (Gouldner, 1960). Both posit the idea of unspecified obligations. "That is, when one party does a favor for another, there is an 
expectation of some future return although exactly when that favor needs to be returned and what form it will take is unclear" (Kaufman, Stamper and Tesluk , 2001, p.437). These unspecified obligations can develop when employees perceive they are supported and cared for. Likewise, an individual who has developed a strong trust in the organization because of the positive way the organization has dealt with him is prone to feel inclined to support and enrich the organization through OCBs.

\section{The Relationship between POS, Trust and OCB}

Employees who feel well supported by their organizations (or have high levels of POS) tend to engage in more OCBs than workers with lower POS levels (Eisenberger, et al., 2001), but Kaufman et al. (2001) clarified that the relationship was stronger for OCBO than for OCBI. Thus, POS contributed more to citizenship behaviors that affect the organization in general, such as defending the company name or promoting the company's products, than to citizenship behaviors that supported individual coworkers. Liu (2009) found the same relationship between POS and OCBO. Because of these findings and other reasons to be discussed later, we decided to use OCBO as our measure of OCB.

Dirks and Ferrin's (2000) meta analysis of the effect of trust in leadership on five work outcome measures indicated that trust is significantly related to OCB. Subsequent studies by Wong, Ngo, Wong $(2003,2006)$ and Wat and Shaffer (2005) provided strong collaborating support for the direct effect of organizational trust on OCB. In addition, employee trust in supervisor has been linked to OCB as a mediator between justice perceptions and OCB (Erturk, 2007; Konovsky \& Pugh, 1994) and as a mediator between leader behavior and OCB (Rubin, et al., 2010). These findings align with social exchange theory and support the idea that employees who trust their organization and perceive that the organization values and supports them will be predisposed to reciprocate with increased OCB. The following hypotheses reflect this point of view:

H1. There is a positive relationship between Organizational Trust and OCBO.

$\mathrm{H} 2$. There is a positive relationship between POS and OCBO.

\section{The Functional Approach to Behavior and McClelland's Needs}

The functional approach to human behavior is the basis for our focus of motivators' moderating effect on the relationship between organizational trust, POS, and OCB. This approach maintains that human behavior is the result of individuals trying to meet their needs or goals (Folger, 1993). Human needs serve as motivators for behavior. We follow the suggestion by Penner, Midili, and Kegelmeyer (1997) that employees consciously choose to engage in OCB because such behavior meets their needs. Rioux and Penner (2001) used the functional approach in their analysis of OCB and identified prosocial value motives and organizational concern motives as strong influences on OCB. Their study of motivators is a departure from earlier studies of individual-related antecedents to OCB which focused on personalityrelated factors (Organ, 1994, Organ \& Ryan, 1995; Chien, 2004; Abu Elanain, 2007; Van Emmerik \& Euwema, 2007; Ilies, Spitzmuller, Fulmer \& Johnson, 2009). While our approach mirrors Rioux and Penner in that we take a functional approach to human behavior, we have chosen to focus on a different set of motivators and to examine their moderating effect on OCB. We have chosen to study the needs for achievement, affiliation, and power which were identified by McClelland (1961) as common motivators shaping human behavior.

Few other researchers have noted these needs as potential antecedents of OCB, but Organ (1994) observed that some OCBs may stem from an employee wanting to play the "role of a dominant parent" or as a "means of establishing status." We believe that these instances may portray individuals with a need for power. Supporting this idea is the finding of Lin (2008) that the need for power-prestige indirectly influences OCBs through the mediation of instrumental and expressive ties (i.e. social network). Organ (1994), in the same article noted above, commented: "if we had to stake our hopes on one measurable 
facet of the person that explains appreciable variance in OCB, the data suggest that it would have something to do with the Big Five's Conscientiousness, properly qualified to include aspects of achievement-striving, activity level, and affiliation.” (p. 475) In that statement, two of McClelland's needs are identified: affiliation and achievement. Engaging in OCBs affords an employee the opportunity to interact with coworkers and to form relationships by providing support and help. Employees may view this as an opportunity to meet a need for affiliation. Johnson's (2008) findings also support the idea that need for achievement and need for affiliation have a significant positive relationship to OCB. These findings indicated that the relationship was strongest when employees perceived that organizational culture and leadership support were high.

Of McClelland's three needs, the need for achievement has received the most attention in studies focusing on OCBs. Neuman and Kickul (1998) included "achievement orientation" in their study of OCB. They noted: "According to Judge and Bretz (1992) achievement is descriptive of concern for the advancement of one's own career and might be operationalized by a willingness to work hard, seeking opportunities to learn new skills, taking on additional responsibilities, or sacrificing personal gratification for work-related objectives." (Newman \& Kickul, 1998, p.267.) The results of their study showed that strong achievement orientation is positively associated with OCB. Similarly, Hui, Organ, and Crooker (1993) found that the variable, "achievement striving," correlates with "compliance," the impersonal form of OCB. The previous comment is one reason we chose to use the impersonal form of OCB i.e., OCBO. We assume that an employee who places a high value for achievement would likely also be one with a high need for achievement so we expect to find that a need for achievement will moderate the relationship between OCB and POS and organizational trust such that a high need for achievement will enhance the relationship between those variables.

In summary, we find enough support in the literature review to expect that the needs for achievement, affiliation and power can be linked to OCB and perhaps can strengthen the relationships between POS, organizational trust and OCB. Specifically, we expect high needs for achievement, affiliation or power will enhance OCB in workers even if they have relatively low trust or low perceived organizational support. Similarly, low needs for achievement, affiliation or power will impede OCB in workers even if they have relatively high trust or perceived high organizational support. These relationships are depicted in Figure 1.

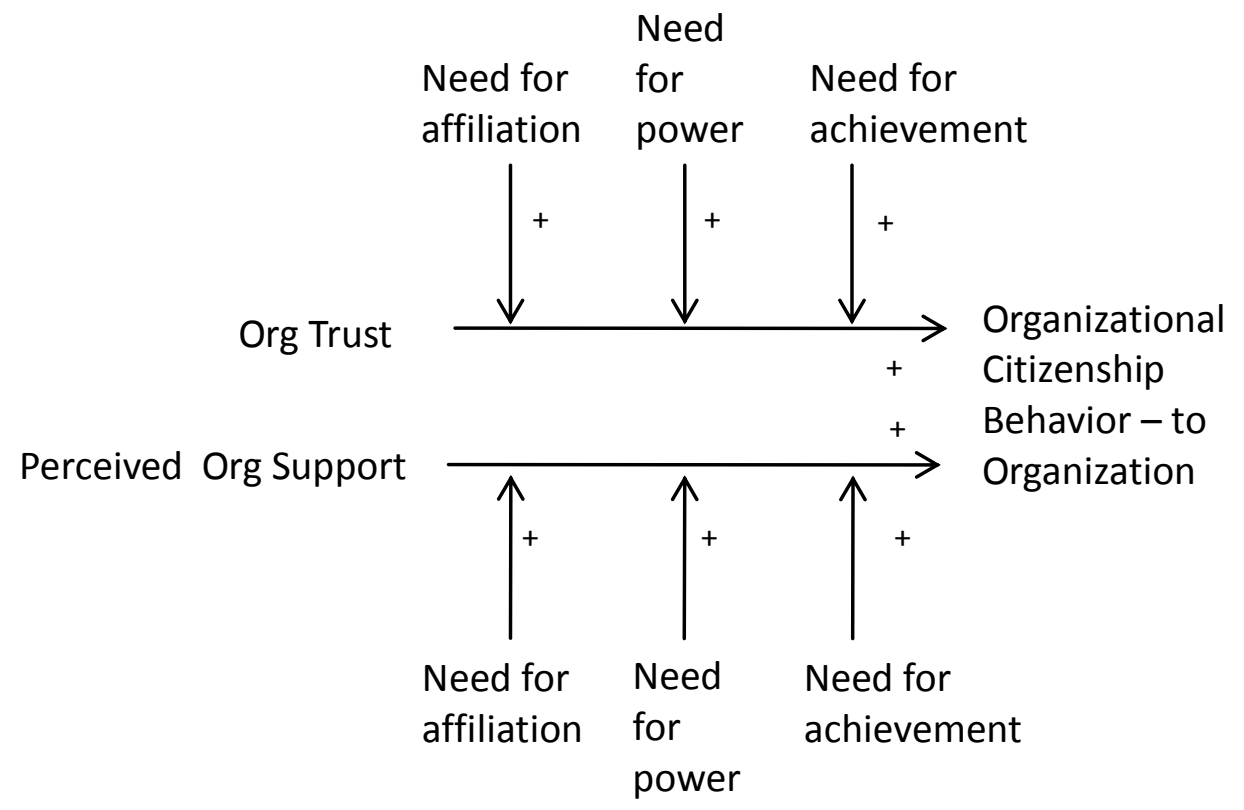

Figure 1. Model of Hypothesized Relationships 
OCBO.

H3a. Need for power will positively moderate the relationship between Organizational Trust and

H3b. Need for power will positively moderate the relationship between POS and OCBO. and OCBO.

H4a. Need for affiliation will positively moderate the relationship between Organizational Trust

H4b. Need for affiliation will positively moderate the relationship between POS and OCBO.

H5a. Need for achievement will positively moderate the relationship between Organizational Trust and OCBO.

H5b. Need for achievement will positively moderate the relationship between POS and OCBO.

\section{Method}

This study is designed to examine how McClelland's needs moderate the relationships between OCB and POS and Organizational Trust. First, we will examine the strength of the relationship between POS and Organizational Trust and OCB. Then we will test the moderating effect of the need for power, affiliation and achievement on the relationships between OCB and POS and Organizational Trust.

\section{Participants and Procedure}

Subjects for the study were contacted through the alumni association of a university in the southwest. 20,000 letters were sent to a random sample of alumni asking them to participate in a longitudinal study on work attitudes. 1207 alumni returned cards stating that they would participate, and the first survey generated 700 useable surveys for a response rate of $57.9 \%$, with subjects working in fifteen different industries. The data in this paper are from the first survey in a series of four. The final sample characteristics included: a) a mean age of 44.23 years; b) $48.8 \%$ male and $51.2 \%$ female; c) average hours worked each week of 45.64; and d) $33.4 \%$ of all respondents classified themselves as managers or executives, $42.3 \%$ classified themselves as professional, and $22.8 \%$ classified themselves as employees.

The survey completed by respondents was entitled "Employee Attitudes about Work" and subjects were asked to complete several questions about their workplace. Before data collection began, subjects indicated their preference for either electronic or paper surveys. 370 respondents completed the survey electronically, and 330 completed a paper survey.

\section{Measures}

Organizational citizenship behavior was measured using Williams and Anderson's (1991) scale for OCBO. Subjects were asked how often they engaged in certain behaviors, with $1=$ never and $7=$ always. Sample items include, "How often do you defend the organization when other employees criticize it?" and "How often do you show pride when representing the organization in public?" We chose to use this measure of OCB because we believe it captures the more visible, less personal dimension of OCB. Organizational trust was measured using an abbreviated version of Cummings and Bromiley's (1996) organizational trust inventory, while perceived organizational support was measured using items from the Survey of Perceived Organizational Support (Eisenberger, Huntington, Hutchison \& Sowa, 1986). Example items from the trust scale included, "I feel my employer is reliable" and "I feel that my 
employer negotiates with me honestly." Perceived organizational support items included, "The organization cares about my opinions" and "Help is available from the organization when I have a problem." Answers were recorded on a 7-point Likert scale with $1=$ strongly disagree and $7=$ strongly agree.

The manifest needs questionnaire (Steers \& Braunstein, 1976) is used to measure need for power, need for achievement, and need for affiliation. There are twelve questions, three for power, four for achievement, and five for affiliation, that are measured using a 7-point Likert scale, with $1=$ strongly disagree and $7=$ strongly agree. Example questions include "I take moderate risks and stick my neck out to get ahead at work" for need for achievement; "I strive to gain more control over events around me at work" for need for power; and "I get satisfaction from being with others more than a lot of other people do" for need for affiliation. This scale has been used in the past with good reliabilities (O'Connor \& Morrison, 2001).

\section{Analysis}

Cronbach alphas were computed to check the reliability of the scales along with correlation analyses to show the relationship between the variables. Table 1 shows the results of these initial analyses.

\section{Results}

Results from the analyses are presented in Table 2. Hypothesis 1, which stated there will be a positive relationship between POS and OCBO, was supported $(F=290.09, p<.001)$. The second hypothesis stating there will be a positive relationship between Organizational Trust and OCBO was also supported $(\mathrm{F}=184.93, \mathrm{p}<.001)$. Hypothesis $3 \mathrm{a}$, postulating a moderating effect of need for

Table 1

Descriptive Statistics, Reliabilities and Correlations

$\begin{array}{lllllllllll}\text { Variables } & \text { Mean } & \text { SD } & 1 & 2 & 3 & 4 & 5 & 6\end{array}$

1. Org Trust

2. POS

3. OCBO

4. Need for Affiliation

5. Need for Power

6. Need for Achievement

$4.98 \quad 1.40$

4.73

1.36

$.81^{* *}$

.99

$.47 * *$

$.55^{* *}$

(.80)

3.66

.84

$.13 * *$

$.18^{* *} .23^{* *}$

4.76

1.13

.02

$.16^{* *}$

$.39 * * \quad .18 * *$

5.29

.004

$\begin{array}{llll}.09 * & .34 * * & .11 * * & .54 * *\end{array}$

Scale reliabilities are noted in the diagonals.

$* *=\mathrm{p}<.01$

$n=700$

power on the relationship between Organizational Trust and OCBO was also supported $(b=-.92, \mathrm{p}<$ .001 ), but in the opposite direction of the prediction. Similarly, Hypothesis 3b, postulating a moderating 
effort of need for power on the relationship between POS and OCBO was supported $(b=-.59, \mathrm{p}<.001)$, but in the opposite direction of the prediction.

Table 2

Results of Hypotheses Predicting Organizational Citizenship Behavior

\begin{tabular}{|c|c|c|c|c|}
\hline & Predictors & F-value & $b$ & Adj $R^{2}$ \\
\hline $\mathrm{H} 1$ & Perceived Org Support & $290.09 * * *$ & $.55 * * *$ & .30 \\
\hline $\mathrm{H} 2$ & Org Trust & $184.93 * * *$ & $.46^{* * *}$ & .22 \\
\hline $\mathrm{H} 3 \mathrm{a}$ & $\begin{array}{l}\text { Org Trust } \\
\text { Need for power } \\
\text { Trust x Need for power }\end{array}$ & $141.90 * * *$ & $\begin{array}{l}1.13 * * * \\
.95 * * * \\
-.92 * * *\end{array}$ & .39 \\
\hline $\mathrm{H} 3 \mathrm{~b}$ & $\begin{array}{l}\text { Perceived Org Support } \\
\text { Need for power } \\
\text { POS x Need for power }\end{array}$ & $151.49 * * *$ & $\begin{array}{l}.92 * * * \\
.65 * * * \\
-.59 * * *\end{array}$ & .41 \\
\hline $\mathrm{H} 4 \mathrm{a}$ & $\begin{array}{l}\text { Org Trust } \\
\text { Need for affiliation } \\
\text { Trust x Need for nAff }\end{array}$ & $71.44 * * *$ & $\begin{array}{r}.47 * * \\
.19 \\
-.04\end{array}$ & .24 \\
\hline $\mathrm{H} 4 \mathrm{~b}$ & $\begin{array}{l}\text { Perceived Org Support } \\
\text { Need for affiliation } \\
\text { POS x Need for nAff }\end{array}$ & $102.55 * * *$ & $\begin{array}{r}.63 * * * \\
.22 * \\
-.14\end{array}$ & .32 \\
\hline $\mathrm{H} 5 \mathrm{a}$ & $\begin{array}{l}\text { Org Trust } \\
\text { Need for achievement } \\
\text { Trust x Need for } n A c h\end{array}$ & $114.00 * * *$ & $\begin{array}{l}.97 * * * \\
.65 * * * \\
-.60 * *\end{array}$ & .34 \\
\hline $\mathrm{H} 5 \mathrm{~b}$ & $\begin{array}{l}\text { Perceived Org Support } \\
\text { Need for achievement } \\
\text { POS x Need for } n \text { Ach }\end{array}$ & $137.89 * * *$ & $\begin{array}{r}.85 * * * \\
.48 * * * \\
-.39\end{array}$ & .39 \\
\hline
\end{tabular}

Hypotheses $4 \mathrm{a}$ and $4 \mathrm{~b}$ predicted that need for affiliation would act as a positive moderator between Organizational Trust and OCBO (H4a) and between POS and OCBO (H4b), but these hypotheses were not supported $(b=-.04, \mathrm{p}<.853$ for $\mathrm{H} 4 \mathrm{a} ; b=-.14, \mathrm{p}<.42$ for $\mathrm{H} 4 \mathrm{~b})$. Hypothesis $5 \mathrm{a}$ proposed that need for achievement would positively moderate the relationship between Organizational Trust and OCBO. The finding was significant $(b=-.60, \mathrm{p}<.01)$, but in the opposite direction of the prediction. Hypothesis $5 \mathrm{~b}$ proposed that need for achievement would positively moderate the relationship between POS and OCBO. This finding was almost significant $(b=-.39, \mathrm{p}<.062)$, but in the opposite direction of the prediction. Figure 2 summarizes the relationships found in the analyses. 


\section{Discussion}

The study posed five hypotheses related to OCBO and possible antecedents. We tested the direct relationship between organizational trust, POS and OCBO. Furthermore, we examined the moderating effect of McClelland's needs for achievement, affiliation and power on the relationships between organizational trust and OCBO and POS and OCBO. Most of the analyses had statistically significant results; however, some of the results showed a significant relationship in a direction opposite of what had been hypothesized.

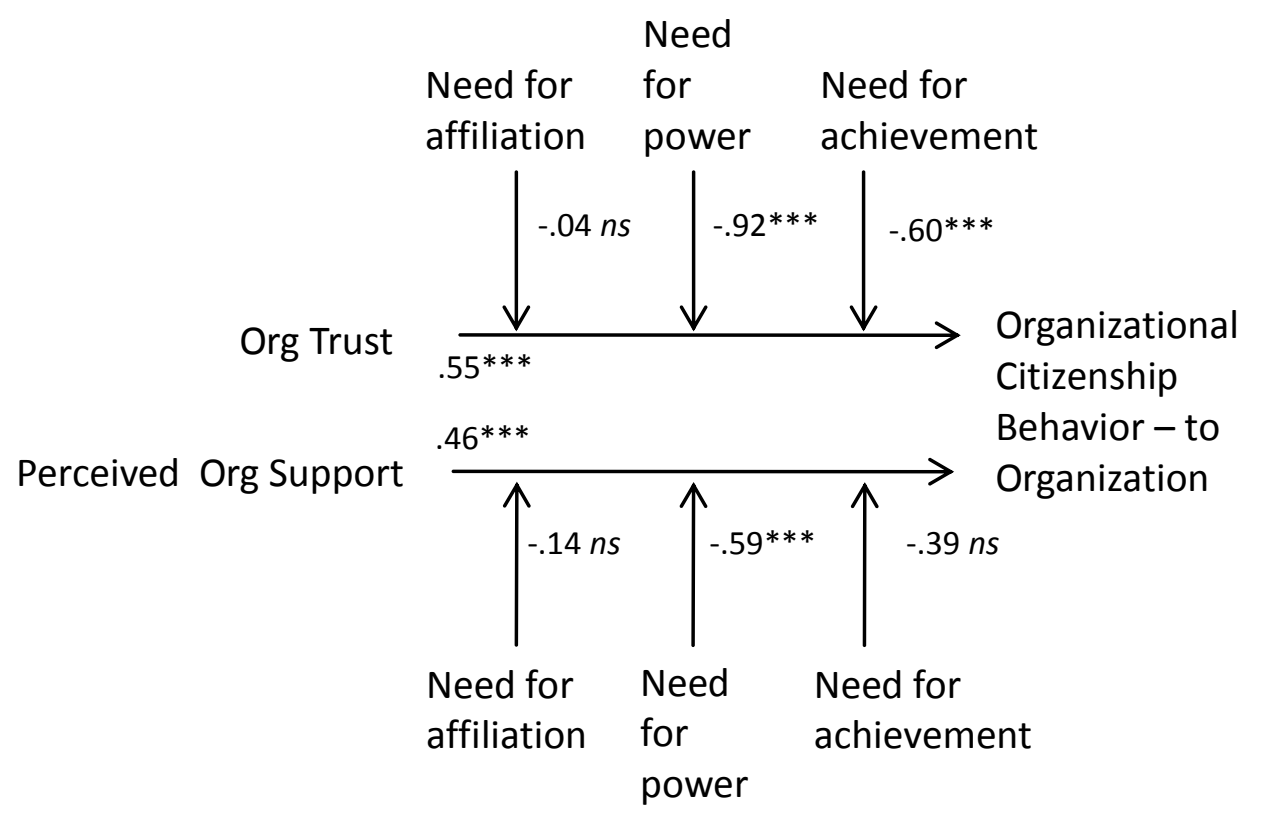

Figure 2. Model with Statistical Results

As expected, the results show that both POS and organizational trust relate positively to OCBO. Employees who feel well supported by their organizations tended to engage in more OCBOs than workers with lower POS levels. Likewise, higher levels of organizational trust were associated with more OCBOs. These results are congruent with earlier studies that found a strong link between OCB and organizational trust (Dirks \& Ferrin, 2000) and between OCB and POS (Eisenberger, et al., 2001).

The search for a moderating effect by McClelland's (1961) needs for achievement, affiliation, and power on the relationship between POS and organizational trust and OCBO had surprising results. Our findings did not support what we expected based on the literature review. We had hypothesized that McClelland's needs would have a positive moderating effect on the relationship between POS and OCBO and between organizational trust and OCBO. However, the need for affiliation had no significant moderating effect on either relationship. This finding does not agree with Johnson's (2008) research which did find a positive relationship between the need for affiliation and OCB. A closer look at the Johnson study shows that the definition of OCB may have caused the discrepancy in the study's findings. Johnson noted that the need for affiliation is more positively related to internal dimensions of OCB i.e. individual initiative, interpersonal helping, and personal industry than to external dimensions (loyal boosterism). The internal focus of this perspective of OCB is more aligned to the behaviors directed at colleagues in the organization. In the current study we did not include such behaviors in our definition of OCB since we used a scale which only measures OCBOs, behaviors directed at the enhancing the organization in general. Our findings indicate that individuals with a high need for affiliation will not be motivated to engage in behaviors that benefit the "impersonal" aspects of an organization, such as its 
"good name." It would be interesting to repeat our study using a definition of OCB that captures more interpersonal dimensions of OCB.

This study of the possible moderating effect of the need for achievement on the relationship between the antecedents and OCB did not align with results from earlier studies. Need for achievement was not a moderator for the relationship between POS and OCBO although it should be noted that it is near significance and negative in its direction. Need for achievement was a moderator in the relationship between organizational trust and OCBO. We expected to find that the higher need for achievement would positively impact the relationship. This expectation is compatible with Johnson's (2008) results. However, our results indicate that a high need for achievement mutes the positive relationship between OCBO and organizational trust. In fact, a low need for achievement strengthens the relationship between trust and OCBO. A negative direction in the moderating effect was also evident when we studied the need for power. The relationships between organizational trust and OCBO and between POS and OCBO were strengthened when employees had low power needs. A high need for power dampened the positive relationship between OCBO, organizational trust and POS. It appears that high power needs redirect the employees away from organizational citizenship behavior even when the employee believes the organization is supportive and trustworthy.

What may have caused the negative direction of the moderating effects of need for achievement and need for power? One possible explanation relies on the assumption that individuals are motivated to act in ways that meet their needs. We know that high achievers seek to attain skills, accomplish tasks, and meet challenges. They are motivated to higher levels of personal accomplishments. A person who has a high need for achievement will perform actions that increase the likelihood that they will be recognized, receive advancements, and acquire sources of influence. Since the common definition of OCB precludes these types of outcomes, it is unlikely that an employee with high needs for achievement would bother to perform OCB. They may not perceive that organizational citizenship behaviors help them meet their needs. Similarly, employees with high power needs will be focused on behaviors that enhance their status or power and will not be inclined to engage in OCB even in a supportive work environment.

Our findings indicate that perceptions of organizational trust or support do not lead to more OCB from employees with high power or achievement needs. These employees most likely redirect their behavior from OCB to behaviors which help them meet their needs. The employees most likely to perform OCB are those with low needs for achievement or power who perceive high organizational trust and support. In other words, employees whose energy is not being spent meeting their personal needs for achievement and power are more likely to choose to spend that energy engaging in other behavior which their trust in the organization or perceptions of organizational support predispose them to engage in, i.e., OCB. Our findings indicate that while low needs may enhance the relationship between OCB antecedents and OCB, high needs for achievement and power impede that relationship.

Levine (2010) proposed a theoretical framework that links emotion and social influence (power) to OCB. In this framework individuals who show a strong control profile, i.e. they have a great deal of social influence, will have more OCB. This may suggest that another possible explanation for our findings is that once individuals who have high needs for achievement or power have had those needs met, they will engage in OCB. We suggest that once those personal needs are met, they are less preoccupied and more likely to engage in other types of behaviors.

However, there is a competing point of view which would suggest that individuals with high needs for power or achievement never really feel that those needs are fully met. If this is the case, the organization is faced with deciding how to cast OCBs in a way that these high need individuals perceive their need for power or their need for achievement is being met. Giving recognition to individuals who perform OCBs, including OCBs in the job appraisals, promoting individuals who are known to perform OCBs are possible ways to cause individuals with high needs for power or achievement to view OCBs in a positive manner. However, this may be a stretch since the present definition for OCB usually implies that the specific behavior is not linked to an external reward. Perhaps we need to rethink this notion. While OCB is behavior that is discretionary and beyond prescribed job tasks, it may be behavior that management should consider making part of "moving ahead" in the organization. Penner et al. (1997) 
noted that " the fact that OCB is a voluntary, extra-role behavior does not mean that OCB goes unnoticed and unappreciated by an organization's leaders, that it has no impact on formal and informal evaluations of an employee's performance or even that people are unaware of the benefits that might result from being a good organizational citizen. To the contrary there is evidence that OCB is noticed, does affect evaluations and that workers know this" $(1997,114)$. If we identify the crux of OCB as prosocial and voluntary behavior, not necessarily unnoticed or unrewarded behavior, we can begin to think of strategic ways that organizations can foster OCB. One strategic approach could be to create organizational cultures that foster OCB.

Drawing from studies of national cultures and OCB, we learn that cultures that are more collectivistic than individualistic are more likely to demonstrate OCB. Lam, Hui and Law (1999) reported that employees in collective cultural contexts are more likely to view OCB as a taken-for-granted part of their performance than are employees in individualistic contexts, and as a result are more likely to demonstrate these behaviors. Analogously, we could assume that organizational cultures characterized by prosocial norms will elicit organizational citizenship behavior. If the organizational culture instills in employees the idea that "going the extra mile," being a good colleague and supportive member of the organization is expected of those employees, it will signal to individuals with high power or achievement needs that OCB is in their best interest. If the organizational culture values OCB, then managers will too. There is empirical evidence that managers do factor in OCB when they evaluate employee performance and allocate rewards (Podsakoff, Whiting, Podsakoff, \& Blume, 2009). It is likely that employees with high achievement or power needs would be motivated to perform OCBs if they realized that their performance evaluations are influenced by the supervisor's perceptions of their organizational citizenship behavior.

\section{Limitations and Implications}

One limitation of the present study concerns the sample being a self-selected sample. Although participants represented a wide variety of industries, the sample is primarily located in the Southwestern U.S., and samples in geographic areas experiencing higher levels of unemployment or underemployment may yield different results. In addition, the data are from a survey administered at one time period only, thus creating a potential problem with common method variance. To reduce this limitation, the survey was designed to minimize the ability of subjects to guess what relationships were being tested. Participants were told the study was about work attitudes and asked to report their honest opinions about work. Because the data for this study are a small part of a larger survey with several different variables, it is unlikely that individual participants could guess what specific relationships were being tested.

The study is also limited by our definition of OCB in terms of OCBO. Before we can make definite judgments on the role of motives in $\mathrm{OCB}$, the results from this study need to be replicated using other samples. It appears that constraining OCB to behaviors that support the overall organization and not including behaviors that support individual coworkers may have eliminated the potential for need for affiliation to appear as a motivator. The need for affiliation would seemingly be relational as is OCBI. Future studies may also benefit from examining the seven dimensions of OCB compiled by Podsakoff, MacKenzie, Paine and Bachrach (2000) and by including other sets of motivators.

Recognizing the limitations of the study, we still feel confident in maintaining that the results support further exploration of the relationship of motivating factors in terms of individual needs and OCB. We believe the results lend substantial support to the notion that motives derived from meeting personal needs can affect how trust and perceived organizational support relate to OCB. From a practical managerial perspective, the results suggest that organizations populated by individuals with high needs for power and achievement should not expect much in the way of organization citizenship behavior directed to the firm in general. Even if employees perceive strong organizational support or have high trust in the organization, their interest in performing altruistically will be dampened because they are motivated to meet their strong personal "needs." Their internal motivation is to meet their own needs rather than to perform extra role behaviors such as OCB. Since OCB has been tied to organizational 
performance, it may be advantageous for an organization to recruit employees with "moderate" instead of "high" needs for achievement and power or to develop a strategy to help "high need" individuals perceive OCB as a way to meet their need for achievement or power. This could be accomplished by creating an organizational culture which has normative expectations of OCB.

\section{References}

Abu Elanain, H. M. (2007). The Five-Factor Model of Personality and Organizational Citizenship Behavior in United Arab Emirates. SAM Advanced Management Journal, 72, 47-57.

Alder, G. S., Noel, T. W., \& Ambrose, M. L. (2006). Clarifying the effects of internet monitoring on job attitudes: the mediating role of employee trust. Information \& Management, 43, 894-903.

Blau, P. (1964). Exchange and Power in Social Life. New York, NY: Wiley.

Chiaburu, D. \& Lim, A. (2008). Manager trustworthiness or interactional justice? Predicting organizational citizenship behaviors. Journal of Business Ethics, 83, 453-467.

Chien, M. H. (2004). An Investigation of the Relationship of Organizational Structure, Employee's Personality and Organizational Citizenship Behaviors. Journal of American Academy of Business, 4, 428-431.

Cummings, L. L. \& Bromley, P. (1996). The Organizational Trust Inventory. In R. Kramer and T. Tyler (Eds.) Trust in Organizations (pp. 302-330). Thousand Oaks, CA: Sage Publications.

DeConinck, J. B. (2010). The effect of organizational justice, perceived organizational support, and perceived supervisor support on marketing employees' level of trust. Journal of Business Research, 63, 1349-1355.

Dirks, K. \& Ferrin, D. (2000). The effects of trust in leadership on empoyee performance, behavior, and attitudes: A meta-analysis. Academy of management best paper proceedings, 1-5.

Eisenberger, R., Armeli, S., Rexwinkel, B., Lynch, P., \& Rhoades, L. (2001). Reciprocation of perceived organizational support. Journal of Applied Psychology, 86, 42-51.

Eisenberger, R., Huntington, R., Hutchison, S., \& Sowa, D. (1986). Perceived organizational support. Journal of Applied Psychology, 71, 500-507.

Ertürk, A. (2007). Increasing organizational citizenship behaviors of Turkish academicians: Mediating role of trust in supervisor on the relationship between organizational justice and citizenship behaviors. Journal of Managerial Psychology, 22, 257-270.

Ferres, N., Connell, J., \& Travaglione, A. (2005). The effect of future redeployment on organizational trust. Strategic Change, 14, 77 -91.

Folger, R. (1993). Justice, motivation, and performance beyond role requirements. Employee Responsibility and Rights Journal, 6, 239- 248.

Gouldner, A. W. (1960). The norm of reciprocity: A preliminary statement. American Sociological Review, 25, 161-178.

Hui. C., Organ, D. \& Crooker, K. (1993). Time pressure, Type A behavior, and organizational citizenship behavior: A field study and an experiment. Bloomington: Unpublished Manuscript.

Ilies, R., Spitzmuller, M., Fulmer, I., \& Johnson, M. (2009). Personality and citizenship behavior: The mediating role of job satisfaction, Journal of Applied Psychology, 94, 945-959.

Johnson, A. (2008). The influence of need for achievement, need for affliation, leadership support and organizational culture on organizational citizenship behavior, Dissertation Abstracts International: Section B, 69(5-B).

Judge, T. \& Bretz, R. (1992). Effects of work values on job choice decisions. Journal of Applied Psychology, 77, 261-271.

Kaufman, J., Stamper, C., \& Tesluk, P. (2001). Do supportive organizations make for good corporate citizens? Journal of Managerial Issues, 13, 436-450.

Konovsky, M. A. \& Pugh, S. D. (1994). Citizenship behavior and social exchange. Academy of Management Journal, 37, 656-669. 
Lam, S. S. K., Hui, C., \& Law, K. S. (1999). Organizational citizenship behavior: Comparing perspectives of supervisors and subordinates across four international samples. Journal of Applied Psychology, 84, 594-601.

Levine, E. L. (2010). Emotion and power (as social influence): their impact on organizational citizenship and counterproductive individual and organizational behavior. Human Resource Management Review, 20, 4-17.

Lin, C. (2008). Examination of gender differences in modeling OCBs and their antecedents in business organizations in Taiwan. Journal of Busniess Psychology, 22, 261-273.

Liu, Y. (2009). Perceived organizational support and expatriate organizational citizenship behavior: The mediating role of affective commitment towards the parent company. Personnel Review, 38, 307319.

McClelland, D. (1961). The Achieving Society. New York: Van Nostrand Reinhold.

McClelland, D. \& Stahl, M. (1986). Managerial and technical Motivation: assessing needs for achievement, power and affiliation. New York: Praeger.

Neuman, G. A. \& Kickul, J. R. (1998). Organizational citizenship behaviors: achievement orientation and personality. Journal of Business \& Psychology, 12, 263-280.

O'Connor W. E. \& Morrison T. G. (2001). A comparison of situational and dispositional predictors of perceptions of organizational politics. The Journal of Psychology, 135, 301-312.

Organ, D. (1988). Organizational citizenship behavior: the good soldier syndrome. Lexington, MA: Lexington Books.

Organ, D. W. (1994). Personality and organizational citizenship behavior. Journal of Management, 20(2), 465-478.

Organ, D. \& Ryan, K. (1995). A meta-analytic review of attitudinal and dispositional predictors of organizational citizenship behavior. Personnel Psychology, 48, 775-802.

Parnell, J. A. \& Crandall, W. R. (2003). Propensity for participative decision making, job satisfaction, organizational commitment, organizational citizenship behavior, and intentions to leave among Egyptian managers, Multinational Business Review, 11, 45-65.

Penner, L. A., Midili, A. R., \& Kegelmeyer, J. (1997). Beyond job attitudes: a personality and social psychology perspective on the causes of organizational citizenship behavior, Human Performance, 10(2), 111-131.

Piccolo, R. F. \& Colquitt, J. A. (2006), Transformational leadership and job behaviors: the mediating role of core job characteristics. Academy of Management Journal, 49(2), 327-40.

Podsakoff, P. M., Ahearne, M., \& MacKenzie, S. B. (1997). Organizational citizenship behavior and the quantity and quality of work group performance. Journal of Applied Psychology, 82, 262-270.

Podsakoff, P. M. \& MacKenzie, S. B. (1994) Organizational citizenship behavior and sales unit effectiveness. Journal of Marketing Research, 31, 351-363.

Podsakoff, P. M., MacKenzie, S. B., Paine, J., \& Bachrach, D. (2000). Organizational citizenship behaviors: A critical review of the theoretical and empirical literature and suggestions for future research. Journal of Management, 26(3), 513-563.

Podsakoff, N. P., Whiting, S. W., Podsakoff, P. M., \& Blume, B. D. (2009). Individual and organizational level consequences of organizational citizenship behaviors: a meta-analysis. Journal of Applied Psychology, 94(1), 122-141.

Rioux, S. M. \& Penner, L. A. (2001). The causes of organizational citizenship behavior: a motivational analysis. Journal of Applied Psychology, 86(6), 1306-1314.

Rubin, R. S., Bommer, W. H., \& Bachrach, D. G. (2010). Operant leadership and employee citizenship: a question of trust? Leadership Quarterly, 21, 400-408.

Smith, C. A., Organ, D. W., \& Near, J. P. (1983). Organizational citizenship behavior: its nature and antecedents. Journal of Applied Psychology, 68(4), 653-663.

Steers, R. M. \& Braunstein, D. N. (1976). .A behaviorally-base measure of manifest needs in work settings. Journal of Vocational Behavior, 9, 251-266. 
Van Emmerik, I. J. \& Euwema, M. C. (2007). Who is offering a helping hand? associations between personality and OCBs, and the moderating role of team leader effectiveness. Journal of Managerial Psychology, 22, 530-548.

Wat, D. \& Shaffer, M. (2005). Equity and relationship quality influences on organizational citizenship behaviors: The mediating role of trust in the supervisor and empowerment. Personnel Review, 34, 406-422.

Williams, L. \& Anderson, S. (1991). Job satisfaction and organizational commitment as predictors of organizational citizenship and in-role behaviors. Journal of Management, 7, 601-617.

Wong, Y., Ngo, H., \& Wong, C. (2003). Antecedents and outcomes of empoyees' trust in Chinese joint ventures. Asia Pacific Journal of Management, 20, 481-499.

Wong, Y. T., Ngo, H. Y., \& Wong, C. S. (2006). Perceived organizational justice, trust, and OCB: A study of Chinese workers in joint ventures and state-owned enterprises. Journal of World Business, 41, 344-355. 